Editorial

\title{
Linking Labour Division within Families, Work-Life Conflict and Family Policy
}

\author{
Ivett Szalma ${ }^{1,2, *}$, Michael Ochsner ${ }^{3}$ and Judit Takács ${ }^{1,4}$ \\ ${ }^{1}$ Centre for Social Sciences, Hungarian Academy of Sciences Centre of Excellence, 1097 Budapest, Hungary; \\ E-Mails: szalma.ivett@tk.mta.hu (I.S.), takacs.judit@tk.mta.hu (J.T.) \\ ${ }^{2}$ Corvinus University of Budapest, 1093 Budapest, Hungary \\ ${ }^{3}$ FORS - Swiss Centre of Expertise in the Social Sciences, University of Lausanne, 1015 Lausanne, Switzerland; \\ E-Mail: michael.ochsner@fors.unil.ch \\ ${ }^{4}$ KWI Essen-Kulturwissenschaftliches Institut, 45128 Essen, Germany \\ * Corresponding author
}

Submitted: 1 September 2020 | Published: 9 October 2020

\begin{abstract}
This thematic issue aims to shed light on the various ways of linking division of labour within families, work-life conflict and family policy in Europe. This editorial briefly introduces key concepts and provides a general overview of the published articles.
\end{abstract}

\section{Keywords}

division of labour; care work; family policy; long-term care; non-paid work; work-family conflict; work-life balance; work-life conflict

\section{Issue}

This editorial is part of the issue "Division of Labour within Families, Work-Life Conflict and Family Policy" edited by Michael Ochsner (FORS Lausanne, Switzerland), Ivett Szalma (Centre for Social Sciences, Hungarian Academy of Sciences Centre of Excellence, Hungary/Corvinus University of Budapest, Hungary) and Judit Takács (Centre for Social Sciences, Hungarian Academy of Sciences Centre of Excellence, Hungary/KWI Essen, Germany).

(C) 2020 by the authors; licensee Cogitatio (Lisbon, Portugal). This article is licensed under a Creative Commons Attribution 4.0 International License (CC BY).

\section{Introduction}

The aim of this thematic issue is to examine the division of labour within couples and families and its relation to work-life conflict from a multilevel perspective. The studies in this issue focus on individual-level factors such as age and gender values, meso-level factors such as employment, work demands and family constructions and macro-level factors such as regions, countries, policy environment and culture. The decisions surrounding how partners share their work are both influenced by these levels and the interactions between them. The main questions this thematic issue proposes to answer include the following: How is the division of labour related to work-life conflict? Which contextual factors can potentially increase equality in the division of labour? What is the role of the situation at the workplace and the labour market? Are there country-specific differences in the division of labour within families and couples and its relation to work-life conflict?

First, we should clarify that labour division is not just an individual decision. The concept of division already incorporates the division with somebody and, thus, we should regard it at least as the partners' common or interdependent decision. However, the partners do not make their decision about labour division in a societal vacuum, but their decision is dependent on attitudes, norms, expectations, opportunities and barriers. Moreover, how labour is divided within families does not only concern the individuals in a family or couple but can have an 
impact on the society; for example, predominant patterns of labour division can influence gender inequalities in other life domains, especially in the labour market (Kotowska \& Matysiak, 2008; McGinnity \& Calvert, 2009) or contribute to decreasing fertility rates (Dommermuth, Hohmann-Marriott, \& Lappegård, 2017; Mills, Mencarini, Tanturri, \& Begall, 2008; Oláh \& Fratczak, 2013).

In this thematic issue we collected eight articles addressing the questions above from different angles, using different theoretical and methodological approaches. In the next section we clarify the basic concepts relevant to this thematic issue.

\section{How to Conceptualise Division of Labour in Families?}

There is a conceptualisation gap between paid employment and non-paid work: The concept of non-paid work is still vaguely defined. Given the lack of a precise definition of non-paid work, there is still no established definition of division of labour within families. What is nonpaid work that is shared within families? According to the OECD, "it refers to the production of goods or services that are consumed by those within or outside a household, but not for sale in the market" (OECD, 2011, p. 10). It is important to note that according to this general definition, the persons dividing labour in the family are not strictly living in the same household nor are they necessarily providing work to persons related by kinship, thus rendering the concept rather diffuse and ambiguous.

At the other extreme in definitions of division of labour within families, researchers define the concept more narrowly, focussing on family members living within the same household and reducing non-paid work within the household to daily routine work, such as cleaning or cooking, and non-routine work, such as repairing and gardening (Hu \& Yucel, 2017; Poortman \& van der Lippe, 2009; Ruppanner, Bernhardt, \& Brandén, 2017). Obviously, in such a narrow definition an important type of non-paid work is missing: care work. Such a narrow conceptualisation is usually due to lack of proper data about caring activities.

Within the bounds of the wide and the narrow definitions, many shades of detail exist. Adding care work to the narrow definition, one has to note that care work itself can have more or less inclusive definitions. Childcare, as the most studied type of care work, is often limited to providing care for children who live with the respondents (see Hank \& Steinbach, 2020; Newkirk, Perry-Jenkins, \& Sayer, 2017). A more complete conceptualisation would include care for the family's elderly, which is still only rarely the case (Grigoryeva, 2017). Other scholars include a more general concept of family care, i.e., care work for family members who are disabled or are suffering from other temporal or chronic vulnerabilities, as all of us have urgent needs for care at various stages in our lives (Lynch, Baker, \& Lyons, 2009).

Family care needs are generally less predictable in terms of timing, duration, intensity, and type of care than childcare, making it an important aspect to consider when examining work-life conflict but also much more difficult to measure. Moreover, with the aging of the European population, elderly care has become an increasingly important component of domestic labour. Still, family care remains almost invisible when nonpaid work is examined: We tend to agree with Bouget, Saraceno, and Spasova (2017, p. 175) that the "recognition of 'carer' status, except for that of mothers of young children, is only in its infancy at EU level."

To complicate matters, care work clearly can be divided between family members who do not live together. Even in the case of childcare, care work can be shared outside the household because of partnership dissolution or other reasons, such as working abroad. In these circumstances, children often stay with their mothers and fathers become non-resident parents. Non-resident fathers can be involved in non-paid work such as taking the children to school, doing homework with them and playing with them. Moreover, care work can be given to family members outside of the household or even the family: Child or elderly care can be carried out by siblings, friends or neighbours, thus blurring the boundaries between care work and volunteer activities, such as in the broad OECD definition.

The topics of non-resident fathers and care work outside of the household are missing from most of the cross-national surveys, which can hinder the better understanding of fathers' involvement in family lives and complexities of family arrangements. Existing research shows that, for fathers, divorce can not only be a challenge, but also a new opportunity and a possibility for new kinds of fathering (Collier \& Sheldon, 2008). Due to the lack of comparative data, this issue cannot be addressed in this thematic issue either, although the resident fathers' participation in non-paid work is discussed regarding several dimensions.

As already noted, the vague conceptualisation of labour division comes with a limited empirical operationalisation. Many international surveys focus on paid employment. For example, in the European Social Survey (ESS), one of the important comparative data sources at the European level, questions related to paid work are placed in the core module, available for each edition, while questions related to non-paid work were placed in a rotating module, fielded in 2004 and 2010, which already indicates that families' division of nonpaid work is perceived as less relevant than that of paid work. The ESS does not stand alone with this practice. The existing general cross-cultural surveys, such as the International Social Survey Programme (ISSP) and the European Values Study (EVS), follow the same strategy: They focus primarily on paid work and only ask about non-paid work on exceptional occasions or in a limited way. The Generations and Gender Survey (GGS) is an exception, providing many details about childcare but, surprisingly, much less about elderly or family care. 


\section{How to Conceptualise Work-Life Conflict?}

The concept of work-life conflict, focussing on the incompatibility between certain aspects of "employees' work lives and nonwork pursuits" (Greenhaus \& Beutell, 1985, p. 76), has attracted increasing attention from scholars during the last decades (see, for example, Byron, 2005; Greenhaus \& Powell, 2003; König \& Cesinger, 2015; Riva, Lucchini, \& Russo, 2019). This can be explained by the profound global changes in private lives and family organisation since the second half of the 20th century leading to increased diversity in the organisation of families and workplaces in the 21st century (Bianchi \& Milkie, 2010). European countries experienced very different trajectories regarding these changes. North-Western European countries saw a substantial increase in female labour force participation: Women no longer tend to withdraw from the labour market after marriage or motherhood but remain employed until retirement (Thévenon, 2009, 2011). While in the Nordic countries, some institutional reforms started to decrease women's burdens (Björnberg, 2011), elsewhere, including in Southern European countries where female labour force participation started to increase only in the 1990s (Thévenon, 2009), women's additional commitment to work was not complemented with the development of the necessary welfare structures to support family-related work (Thévenon, 2011). At the same time, Central-Eastern European post-socialist countries experienced a substantial decline in female labour force participation throughout the 1990 s because of the economic restructuring from state-socialist full employment to market economies (Pignatti, 2016). This transition also brought a rise in work pressure and cuts in welfare services, leaving the burden of care on families, especially mothers (Hobson, Fahlén, \& Takács, 2011) in a process of re-familisation (Saxonberg \& Sirovátka, 2006).

Despite researchers' and policy makers' interest in work-life conflict, the concept is defined in different ways. Already different terms are used to describe similar issues: work-life conflict, work-life balance, work-family conflict. Here, for sake of simplicity, we use work-life conflict as a term encompassing all connotations of conflicts between the work and life realms.

Greenhaus and Beutell (1985) suggested in their seminal work that work-life conflict arises from simultaneous pressures from the work and non-work domains that are incompatible in certain aspects. They distinguish between three types of conflict. First, there might be a time incompatibility when one domain asks for attention for too much time to fulfil the obligations in the other (often referred to as time-based work-life conflict). Second, there might be difficulties to comply with demands from one domain because of strain, leading to not being able to pay enough attention to the other domain (often referred to as strain-based work-life conflict). Third, behaviour might be required in one role that makes it difficult to fulfil the requirements of the other role (often referred to as behaviour-based work-life conflict). A meta-analysis on the basis of more than 60 studies identified an important distinction: Conflicts can go in both directions, i.e., there might be interference of work with family (leading to work-family conflict) or interference of family with work (leading to family-work conflict; see Byron, 2005). Recently, a cognition-based approach to work-life conflict was proposed, interpreting "work-life ideologies as an individual-level construct that captures beliefs regarding how work and life are related" (Leslie, King, \& Claire, 2019, p. 74). However, empirical studies tend to concentrate mainly on time and strain-based aspects of work-life conflict, as operationalising other (for example, emotional) aspects can be more challenging (Steiber, 2009).

Research comparing issues of work-life conflict across European countries or globally relies mainly on two cross-cultural data sets having fielded thematic modules related to work-life conflict: the ISSP 2012 and its earlier iteration in 2002 (ISSP Research Group, 2016) and the ESS round 5 in 2010 and its earlier iteration in 2004 (ESS, 2012). Their operationalisations are similar, but both come with issues of conceptualisation: The ISSP offers four items, two measuring work-family conflict and two reflecting family-work conflict. However, while work-family conflict includes an item each for time and strain-based conflict, both items for the family-work conflict are strain-based. On the other hand, the ESS provides six items to measure work-life conflict, including work-family conflict and adding work's impact on life more generally and on partnership. However, while interference between family and work (family-work conflict) is restricted to the family realm, the interference of work with the private realm does not address workfamily conflicts but rather work-life conflicts in general, i.e., asks not about problems related to family but about free time. Despite these conceptual inconsistencies, the two main data sources for cross-cultural investigation of work-life conflict offer many possibilities to study the phenomenon and hopefully the thematic modules of these surveys will soon be repeated.

Some contributions in this thematic issue rely on ISSP and ESS data and therefore use the conceptualisations of work-life conflict used in these survey projects, coming with the issues described above. But we think that as long as the readers have these issues in mind and are aware of the general difficulties of the conceptualisation and measurement of the concepts involved, the data presented still provides us with valuable insights.

\section{Overview of the Contributions}

With this thematic issue we aim at linking labour division within families, work-life conflict and family policy. We received a diverse set of articles approaching the topic from many different angles, using different approaches and applying qualitative, quantitative and mixed methods. Some of the articles are comparative 
while others describe one case in detail. The examined countries are also very diverse, including Northern, Western and Central Eastern European countries or a global sample.

In the first article, Theocharis Kromydas pays special attention to the period of the economic crisis after the global financial crisis in 2007-2008. He finds that the level of education is especially linked to work-life conflict in times of crisis. Moreover, women are more affected by the crisis in terms of employment, but also in terms of work-life conflict although education can have a cushioning effect on the increase in work-life conflict during the crisis for women.

However, not only education is linked to work-life balance and labour division; social class too plays an important role. In her article, Daria Ukhova focusses on post-socialist Europe in the period between 1994-2012 because this region is particularly notorious for high inequality in the gendered division of domestic labour. On the basis of the ISSP module "Family and Changing Gender Roles," she finds that the gender division of domestic labour did not change substantially during the post-socialist period. The article also reveals that the widespread argument that post-socialist countries go through a wave of traditionalization is not generally valid when controlling for social class. Traditionalisation seems to be the typical trajectory only for lower class households across most of the analysed countries, while the higher-class households follow similar paths as in other European countries.

Besides class, there are cultural factors affecting preferences for models of labour division within families and couples. Regula Zimmermann and Jean-Marie LeGoff examine differences in preferences for labour division in two regions of Switzerland and show that gender culture can differ essentially even within one country. Using indepth interviews, the authors reveal that gendered culture plays out before the birth of the child. Before becoming parents, most French speaking women and men consider it ideal to share paid and non-paid work equally as parents, whereas their German speaking counterparts prioritise fathers' breadwinning and mothers' caregiving model. The transition to parenthood, however, reinforces that men should be the main breadwinner-not only in the German speaking part, but also in the French speaking part, couples share labour in a more inegalitarian way than they had anticipated. This surprising result can be explained by policy influence: the organisation of labour division is not only shaped by individual gender norms, but also by the (in)availability of welfare services. Not only in the German but also in the French part of the country, parents face a limited number of places in childcare facilities and have to cope with a rather short maternity leave and the non-existence of paternity leave.

As shown in the qualitative study by Zimmermann and LeGoff, work-family arrangements are not always in line with the examined couple's attitudes. Christina Bornatici and Marieke Heers thus examine the effect that the incongruence between role attitudes and the achieved family arrangement have on work-life conflict for partners in a sample of 37 countries. They find evidence that individuals having egalitarian attitudes and an egalitarian arrangement have the lowest levels of work-family conflict. However, congruence between attitudes and arrangement does not necessarily lead to lower levels of work-family conflict. Somewhat surprisingly, couples having traditional attitudes and a traditional labour division arrangement experience the highest work-family conflict levels. Between the two are the individuals experiencing inconsistency between their attitudes and labour division arrangement. According to the authors, those who have consistent traditional attitudes and arrangements experience more pressure to completely fulfil their role when each partner is mainly (or exclusively) responsible for a specific role. Their analysis also reveals that not just the individual attitudes and arrangements are important, but also the context: Egalitarian attitudes and arrangements can be most efficiently implemented in cultural and policy contexts that support such egalitarian arrangements.

Besides individual attitudes, the meso and macro levels regarding gender norms and work ethic can also influence labour division in a couple. Nikolett Geszler examines how fathers use flexibility to reconcile work-family conflict in a case study using 43 personal interviews with fathers in managerial positions in a Hungarian subsidiary of a Scandinavian multinational company. While Scandinavian societies are well-known for their longstanding policy legacy of promoting gender equality and work-family balance, Hungarian society can be considered as a traditional one. The project investigates whether the organisational culture in a Swedish company can have an influence on division of household labour among manager fathers in Hungary. Geszler's results show how difficult it can be for fathers to take family time even in companies with the Swedish reputation regarding progressive role models. Work flexibility is more likely to be used to improve productivity than to reconcile work-family issues because at the meso level, i.e., at the level of the company or employer, work-life balance is seen as an individual issue while at the macro level, i.e. at the level of Hungarian society, fathers are pushed to invest in their careers to assure their breadwinner roles.

Beáta Nagy complements Geszler's research by focussing on 20 manager women in Hungary. She explores the impact of the use of mobile technology on their work-life conflict. Hungary is an interesting case since the neoliberal change of the corporate sector took place at the same time when refamilisation was promoted by the state. Thus, manager mothers are hit hard by the competing demands of work and family. The interviewees believe that they can manage to build a professional career whilst running a family with the help of mobile devices. What they often forget is that, given the availability of the devices, the companies can demand full commitment at any time. The women take steps to 
protect themselves from their job on their own, which for some reduces work-life conflict, however, only at an individual level, not resolving the structural problem of being a mother (or caring father) manager.

Following this contribution is an article dealing with parental leave policies. Jolanta Aidukaite and Donata Telisauskaite-Cekanavice present an original comparative analysis between different models of parental leave policies in two countries, Sweden and Lithuania. They use a mixed methods approach including 30 expert interviews and a population survey to compare parental leave policies from experts' as well as citizens' views. The authors find that while Swedish policies aim at enhancing fatherhood by employing defamilialism, Lithuanian policies focus on financial security of families and on kinship familialism as grandparents are entitled to take parental leave. In Sweden, the policies enjoy enormous support in the population and can be seen as a national pride. The Lithuanian population is more sceptical, in contrast to the experts' opinion who judge Lithuanian family policy among the best in Europe.

Not only do parental policies differ considerably among countries, but so do family policies in general, including care for the elderly or the disabled. As the previous contributions have shown, such policies affect how labour within families and couples is organised. Attila Bartha and Violetta Zentai use fuzzy set ideal type analysis (FSITA) to interpret the configurations of long-term care in Europe. Long-term care is a particularly important issue given the demographic aging all over Europe. The authors find that while the richer Northern European countries can afford generous long-term care policies supporting more equal labour divisions within families and couples, some less affluent countries also find ways to support more equal family arrangements. However, a caveat applies: It is likely that gaining more equal family arrangements has its foundation in externalising family work to migrants, which can reinforce work-situations characterised by increasing gendered inequalities for $\mathrm{mi}$ grants and their families.

\section{Conclusion}

In this thematic issue we offer the reader a set of eight articles addressing the link between the division of labour within families, work-life conflict and family policy from different perspectives widening our knowledge on the subject by including several under-researched aspects. We propose the understanding of labour division as a multilevel concept: At the individual level, many contributions include care work in their conceptualisation of labour division in couples; at the meso level, organisational constraints imposed by employers are considered; at the macro level, gender norms (to be understood as interactions between cultural norms and policies, mutually shaping each other) are taken into account, constraining the range of decisions that couples can reasonably take. The eight contributions are complemented by an com- mentary summarising the thematic issue and pointing to aspects in need of future scrutiny.

We are convinced that this thematic issue can help to develop our knowledge on labour division within families and couples, work-life conflict and family policy further and contribute to a better understanding of the relationships between them. The three points raised by the authors and editors of this thematic issue, i.e., inclusion of care work in the conceptualisation of division of labour-also going beyond the nuclear family-the multilevel nature of the relationship between labour division and work-life conflict as well as the consideration of values regarding labour division and gender at each level will contribute to advancing theories and classifications for family policy and give valuable insights for policy development.

\section{Acknowledgments}

The preparation of this thematic issue by Michael Ochsner and Ivett Szalma was supported by the Academic Publishing Workshop Award (H2020 ESS-SUSTAIN). The contribution of Judit Takács was supported by the Academy in Exile Fellowship at the Kulturwissenschaftliches Institut (KWI), Essen.

\section{Conflict of Interests}

The authors declare no conflict of interests.

\section{References}

Bianchi, S. M., \& Milkie, M. A. (2010). Work and family research in the first decade of the 21st century. Journal of Marriage and Family, 72(3), 705-725.

Björnberg, U. (2011). Gender and power in families and family policies. Sweden in the Nordic context. Sociologica, 1, 1-16.

Bouget, D., Saraceno, C., \& Spasova, S. (2017). Towards new work-life balance policies for those caring for dependent relatives? In B. Vanhercke, S. Sabato, \& D. Bouget (Eds.), Social developments in the European Union 2017 (pp. 155-180). Brussels: ETUI and OSE.

Byron, K. (2005). A meta-analytic review of work-family conflict and its antecedents. Journal of Vocational Behavior, 67(2), 169-198.

Collier, R., \& Sheldon, S. (2008). Fragmenting fatherhood: A socio-legal study. Oxford: Hart.

Dommermuth, L., Hohmann-Marriott, B., \& Lappegård, T. (2017). Gender equality in the family and childbearing. Journal of Family Issues, 38(13), 1803-1824.

European Social Survey. (2012). ESS round 5 (Data file edition 3.2) [Data set]. Bergen: Norwegian Centre for Research Data.

Greenhaus, J. H., \& Beutell, N. J. (1985). Sources of conflict between work and family roles. Academy of Management Review, 10(1), 76-88.

Greenhaus, J. H., \& Powell, G. N. (2003). When work and 
family collide: Deciding between competing role demands. Organizational Behavior and Human Decision Processes, 90(2), 291-303.

Grigoryeva, A. (2017). Own gender, sibling's gender, parent's gender: The division of elderly parent care among adult children. American Sociological Review, 82(1), 116-146. https://doi.org/10.1177/ 0003122416686521

Hank, K., \& Steinbach, A. (2020). The virus changed everything, didn't it? Couples' division of housework and childcare before and during the Corona crisis. Journal of Family Research. Advance online publication. https://doi.org/10.20377/jfr-488

Hobson, B., Fahlén, S., \& Takács, J. (2011). Agency and capabilities to achieve a work-life balance: A comparison of Sweden and Hungary. Social Politics, 18(2), 168-198.

Hu, Y., \& Yucel, D. (2017). What fairness? Gendered division of housework and family life satisfaction across 30 countries. European Sociological Review, 34(1), 92-105. https://doi.org/10.1093/esr/jcx085

ISSP Research Group. (2016). International social survey programme: Family and changing gender roles IV-ISSP 2012 [Data set]. https://doi.org/10.4232/ 1.12661

König, S., \& Cesinger, B. (2015). Gendered work-family conflict in Germany: Do self-employment and flexibility matter? Work, Employment and Society, 29(4), 531-549.

Kotowska, I. E., \& Matysiak, A. (2008). Reconciliation of work and family within different institutional settings. In C. Höhn, D. Avramov, \& I. Kotowska (Eds.), People, population change and policies (pp. 299-318). Dordrecht: Springer.

Leslie, L., King, E. B., \& Claire, J. A. (2019). Work-life ideologies: The contextual basis and consequences of beliefs about work and life. Academy of Management Review, 44(1), 72-98.

Lynch, K., Baker, J., \& Lyons, M. (2009). Introduction. In K. Lynch, J. Baker, \& M. Lyons (Eds.), Affective equality: Who cares? Love, care and injustice (pp. 1-11). London: Palgrave Macmillan.

McGinnity, F., \& Calvert, E. (2009). Work-life conflict and social inequality in Western Europe. Social Indicators Research, 93, 489-508.

Mills, M., Mencarini, L., Tanturri, M. L., \& Begall, K. (2008). Gender equity and fertility intentions in Italy and the
Netherlands. Demographic Research, 18, 1-26.

Newkirk, K., Perry-Jenkins, M., \& Sayer, A. G. (2017). Division of household and childcare labor and relationship conflict among low-income new parents. Sex Roles, 76, 319-333. https://doi.org/10.1007/s11199016-0604-3

OECD. (2011). OECD social indicators: Society at a glance 2011. Paris: OECD Publishing. https://doi.org/ 10.1787/soc_glance-2011-en

Oláh, L. S., \& Fratczak, E. (Eds.). (2013). Childbearing, women's employment and work-life balance policies in contemporary Europe. Basingstoke and New York, NY: Palgrave Macmillan.

Pignatti, N. (2016). Encouraging women's labor force participation in transition countries. IZA World of Labor. http://dx.doi.org/10.15185/izawol.264

Poortman, A., \& van der Lippe, T. (2009). Attitudes toward housework and child care and the gendered division of labor. Journal of Marriage and the Family, 71, 526-541.

Riva, E., Lucchini, M., \& Russo, M. (2019). Societal gender inequality as moderator of the relationship between work-life fit and subjective well-being: A multilevel analysis across European countries. Social Indicators Research, 143(2), 657-691.

Ruppanner, L., Bernhardt, E., \& Brandén, M. (2017). Division of housework and his and her view of housework fairness: A typology of Swedish couples. Demographic Research, 36, 501-524.

Saxonberg, S., \& Sirovátka, T. (2006). Failing family policy in post-communist Central Europe. Journal of Comparative Policy Analysis: Research and Practice, 8(2), 185-202. http://doi.org/10.1080/ 13876980600682089

Steiber, N. (2009). Reported levels of time-based and strain-based conflict between work and family roles in Europe: A multilevel approach. Social Indicators Research, 93, 469-488.

Thévenon, O. (2009). L'augmentation de l'activité des femmes en Europe: Progrès de la conciliation ou polarisation des comportements? [Increased women's labour force participation in Europe: Progress in the work-life balance or polarization of behaviours?]. Population, 64(2), 235-272.

Thévenon, O. (2011). Family policies in OECD countries: A comparative analysis. Population and Development Review, 37, 57-87.

\section{About the Authors}

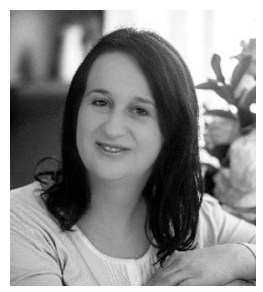

Ivett Szalma is a Postdoctoral Fellow at the Centre for Social Sciences, Hungarian Academy of Sciences Centre of Excellence and an Associate Professor at the Corvinus University of Budapest, and the Head of the Family Sociology Section of the Hungarian Sociological Association. Her research topics include the effects of economic crises on work-life conflicts, post-separation fertility, childlessness, non-resident fatherhood, measurement of homophobia and adoption by same-sex couples. 


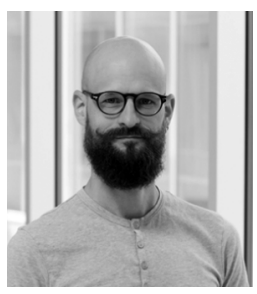

Michael Ochsner is a Senior Researcher at FORS-Swiss Centre of Expertise in the Social Sciences, Lausanne. He is a survey methodologist involved in the implementation of the ESS, the ISSP and the EVS in Switzerland. His research covers welfare policy and legitimacy of the state, work-life conflict, cultural differences in survey research, representation bias and survey modes. He is also a specialist on research quality and evaluation in the social sciences and humanities. Image (C) felix imhof

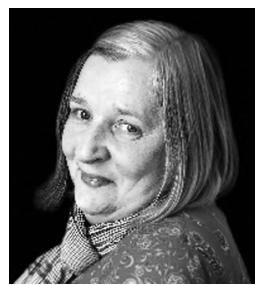

Judit Takács is a Research Chair at the Centre for Social Sciences, Hungarian Academy of Sciences Centre of Excellence, responsible for leading research teams and conducting independent research on topics including family practices, work-life balance issues, childlessness as well as social history of homosexuality, social exclusion/inclusion of LGBTQ+ people, HIV/AIDS prevention. Currently she is an Academy in Exile fellow at the Kulturwissenschaftliches Institut (KWI), Essen. 